\title{
Evaluation on the Stability of Vertical Mine Shafts below Thick Loose Strata Based on the Comprehensive Weight Method and a Fuzzy Matter-Element Analysis Model
}

\author{
Wenquan Zhang, ${ }^{1,2}$ Zaiyong Wang $\mathbb{D}^{1,2}$ Jianli Shao, ${ }^{1,2}$ Xianxiang Zhu $\mathbb{D}^{1,2}$ Wei Li, ${ }^{1,2}$ \\ and Xintao $\mathrm{Wu}^{1,2}$ \\ ${ }^{1}$ College of Mining and Safety Engineering, Shandong University of Science and Technology, Qingdao 266590, China \\ ${ }^{2}$ State Key Laboratory of Mine Disaster Prevention and Control (Cultivation), Shandong University of Science and Technology, \\ Qingdao 266590, China
}

Correspondence should be addressed to Zaiyong Wang; zaiyongwang@163.com

Received 16 September 2019; Revised 25 October 2019; Accepted 6 November 2019; Published 26 November 2019

Academic Editor: Paulo Fonseca

Copyright (c) 2019 Wenquan Zhang et al. This is an open access article distributed under the Creative Commons Attribution License, which permits unrestricted use, distribution, and reproduction in any medium, provided the original work is properly cited.

\begin{abstract}
Damage to mine shafts located below thick loose aquifers, caused by coal seam mining, can seriously affect the operational safety of mines. In view of such a problem, the comprehensive weight method and the fuzzy matter-element analysis method were used to analyze and evaluate the stability of mine shafts below thick, loose aquifers. Based on data relating to shaft structure parameters collected from fifteen damaged shafts in coal mines in East China, a comprehensive analysis was performed. The results showed that (1) the two indexes of surface subsidence velocity and water level drop value at the bottom of a loose aquifer have a large influence on the stability of shafts below thick loose aquifers, and (2) the predicted results of thirteen sets of samples were the same as the results measured during actual production; the accuracy of the model was $86.67 \%$. The comprehensive weight method and the fuzzy matter-element analysis model both show good reliability for evaluating the stability of mine shafts below thick loose aquifers and can provide a scientific reference for the analysis of the stability of mine shafts in areas with thick loose strata, as well as for the design of comprehensive control plans that could subsequently be implemented.
\end{abstract}

\section{Introduction}

Indirect mining damage to vertical mine shafts located below thick loose aquifers is a newly identified potential geological disaster facing mines. Underground mines located below such aquifers are widely distributed in Huainan, Huaibei, Xuzhou, Jining, and other regions of China. The geological conditions around coal seams beneath thick loose aquifers are complex. The thickness of thick loose strata exerts great stress on any shaft located below them. At the same time, the bottom stratum of thick loose strata is a layered structure, with the subaquifer and the subaquiclude alternately connected, through which water can easily flow following mining disturbance, posing a hazard to shafts [1-4]. During the mining process in the mining face, the overburden layer of the coal seam gradually bends and sinks, generating mining fissures. It is easy to run through the bottom loose aquifer at the upper part of the bedrock, causing water and sand to gradually penetrate downward along these mining fissures, resulting in consolidation of the loose aquifer due to water losses [5]. In the long-term, this water loss process leads to consolidation and compression occurring in the aquifer due to it being affected by the load of the upper loose strata, resulting in structural damage to shaft walls [6-9]. A schematic diagram showing structural damage to a shaft following disturbance by mining is shown in Figure 1.

Following instability deformation of loose sections of a vertical shaft, an affected mine will generally be shut down for maintenance. In severe cases, a large amount of water 

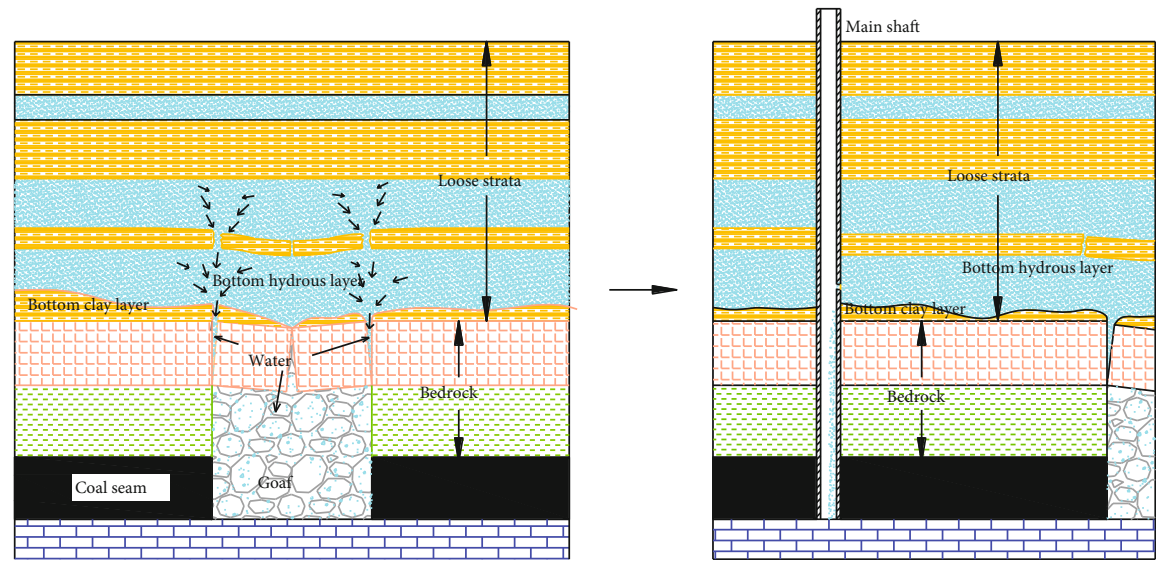

FiguRE 1: A schematic diagram showing the deformation and failure process of shafts below thick unconsolidated layer.

TABLE 1: Examples of instability failure accidents that have occurred in mine shafts [10, 11].

\begin{tabular}{|c|c|c|c|}
\hline Mining area & Shaft name & Time of accident & Fracture conditions \\
\hline \multirow{3}{*}{ Xuzhou } & $\begin{array}{l}\text { Main shaft of Zhang } \\
\text { Shuanglou Coal Mine }\end{array}$ & 1987.8.7 & $\begin{array}{l}\text { The shaft wall was fractured, blocks fell, and water seepage occurred in } \\
\text { the damaged area to a limited extent. }\end{array}$ \\
\hline & $\begin{array}{l}\text { Auxiliary shaft of Zhang } \\
\text { Shuanglou Coal Mine }\end{array}$ & 1987.7.29 & $\begin{array}{l}\text { The shaft wall was fractured. The shaft annulus reinforcement was bent. } \\
\text { The cage-girder was distorted. A large amount of groundwater } \\
\text { instantaneously burst into the shaft. The water inflow was } 60.5 \mathrm{t} / \mathrm{h} \text {, } \\
\text { which flooded the shaft and the roadway. }\end{array}$ \\
\hline & $\begin{array}{l}\text { Air shaft of } \\
\text { Zhangshuanglou } \\
\text { Coal Mine }\end{array}$ & 1992.6 .4 & $\begin{array}{c}\text { The shaft wall was fractured, and a large amount of material fell down. } \\
\text { The shaft wall was moved inward by } 300 \mathrm{~mm} \text { due to the compressive } \\
\text { force. The damage was serious. }\end{array}$ \\
\hline \multirow{4}{*}{ Huaibei } & $\begin{array}{l}\text { Auxiliary shaft of } \\
\text { Linhuan Coal Mine }\end{array}$ & 1987.7.12 & $\begin{array}{l}\text { The concrete in the shaft wall fell in pieces in a ring. The depth was } \\
\text { between } 200 \text { and } 250 \mathrm{~m} \text {. The reinforcement was exposed and bent backward. } \\
\text { The water inflow at the rupture was } 1 \mathrm{t} / \mathrm{h} \text {, and the headframe was displaced. }\end{array}$ \\
\hline & $\begin{array}{l}\text { Main shaft of Haizi } \\
\text { Coal Mine }\end{array}$ & 1988.10 .6 & $\begin{array}{l}\text { The concrete in the shaft wall was spalled, and the reinforcement was } \\
\text { exposed and bent backward. Some parts of the shaft wall were } \\
\text { underwater, and a cage-jamming accident occurred. }\end{array}$ \\
\hline & $\begin{array}{l}\text { West air shaft of } \\
\text { Linhuan Coal Mine }\end{array}$ & 1993.7 & $\begin{array}{l}\text { The concrete in the shaft wall fell off in pieces. The depth was between } \\
200 \text { and } 250 \mathrm{~m} \text {. The reinforcement was exposed and bent backward. }\end{array}$ \\
\hline & $\begin{array}{l}\text { Auxiliary shaft of } \\
\text { Wugou Coal Mine }\end{array}$ & 2013.6 & $\begin{array}{l}\text { Water burst from the connecting-bolt gaps of the cage-guide, which was } \\
256 \mathrm{~m} \text { from the surface, and the water level increased. Water appeared } \\
\text { in two sand holes on the right-hand side of the shaft wall. }\end{array}$ \\
\hline \multirow{2}{*}{ Huainan } & $\begin{array}{l}\text { East air shaft of } \\
\text { Panyi Coal Mine }\end{array}$ & 1992.7.27 & $\begin{array}{l}\text { The surface of the shaft wall cracked; the maximum width of the crack was } \\
1.3 \mathrm{~m} \text { and the depth was } 100 \mathrm{~mm} \text {. Water seepage occurred in local areas. }\end{array}$ \\
\hline & $\begin{array}{l}\text { Auxiliary shaft of } \\
\text { Banji Coal Mine }\end{array}$ & 2009.4.18 & $\begin{array}{l}\text { A large volume of water inrush occurred, with a water inflow volume } \\
\text { of } 10,000 \mathrm{~m}^{3} / \mathrm{h} \text {. The fan stopped running and the entire mine was flooded. }\end{array}$ \\
\hline \multirow[b]{2}{*}{ Jining } & $\begin{array}{l}\text { Main shaft of Baodian } \\
\text { Coal Mine }\end{array}$ & 1995.7.12 & $\begin{array}{l}\text { The cage-guide joints were compacted, the pipelines were compressed } \\
\text { and bent, and multiple horizontal cracks appeared on the concrete surface. }\end{array}$ \\
\hline & $\begin{array}{l}\text { Main shaft of } \\
\text { Xinglongzhuang } \\
\text { Coal Mine }\end{array}$ & 1997.6 .23 & $\begin{array}{l}\text { The cage-guide joints were compacted, the pipelines were compressed } \\
\text { and bent, and multiple horizontal cracks appeared on the concrete surface. } \\
\text { The vertical reinforcement was bent and exposed. }\end{array}$ \\
\hline Heze & $\begin{array}{l}\text { Main shaft of Guotun } \\
\text { Coal Mine }\end{array}$ & 2015.6 .1 & $\begin{array}{l}\text { Six pieces of cage-guide on the first compressible shaft wall in the shaft } \\
\text { came loose and dropped, resulting in damage to the skip tail rope and } \\
\text { the support mechanism at the shaft bottom. }\end{array}$ \\
\hline
\end{tabular}

and sand can burst through the shaft wall and damage the shaft, putting the lives of underground workers in serious danger and causing huge economic losses for the mine. According to statistics, since the 1980s more than twenty mine shafts in Huaibei, Huainan, Xuzhou, Jining, and other regions have suffered various degrees of damage, which have seriously affected the safe production of coal in each mine (see Table 1).

There is a need, therefore, for an in-depth analysis of nonmining failures of mine shafts. It is important to explore the various factors influencing this and their degrees of correlation. The accurate evaluation of the stability of mining 
shafts under thick loose aquifers will be useful for the prediction and prevention of disasters and accidents caused by nonmining damage in shafts located below thick loose aquifers, and will be of great practical significance to ensure the safety and reliability of mining processes [12-16].

To date, most studies of mine shafts in China and other countries have focused on their failure mechanisms and ways to address these failures, which usually involves the use of solid filling technology to control the deformation of shafts $[17,18]$. There have been relatively few studies that have evaluated the stability of mining shafts below thick loose aquifers. Liu et al. [19] constructed a system for predicting nonmining fractures in coal mine shafts, based on the concept of an artificial neural network. Kong [20], using theoretical analysis, numerical simulation, and a field measurement method, performed an in-depth analysis of the disastercausing factors in frozen vertical shafts below deep, thick overburden, and determined the spatiotemporal dynamic processes involved in shaft instability. Huang and Guo [21] established a system for monitoring the stability of vertical shafts by means of observation, through the arrangement of a number of on-site observation points. Liu et al. [22] analyzed a number of factors affecting the stability of shafts and built a vertical shaft stability evaluation model in combination with fuzzy clustering analysis theory. Xu et al. [23] established shaft safety evaluation models based on the minimum distance discrimination method to predict the ranking of the stability of mine shafts after three years, using as examples the main shaft, auxiliary shaft, east air shaft, and west air shaft of Xinglongzhuang Coal Mine. Lyu and Wang [24] established an automatic, multilayer, deformation monitoring system for the complex geological effects resulting from the weakly cemented formation of a shaft wall, to evaluate changes in the stability of vertical shaft walls. These scholars studied and analyzed mine shafts using various theoretical methods and technical means, and their work has greatly improved the prediction and control of disasters and accidents caused by nonmining failures of shafts below thick loose strata. However, in view of the complex geological conditions that influence mining areas under thick loose aquifers, some problems remain around shaft stability evaluation and prediction that urgently need to be solved. With respect to numerical simulations, previously, the simulation process has been somewhat simplified, and it is difficult to represent the true geological changes. The main factors affecting the deformation and failure of shafts and their ranking have yet to be determined theoretically. Existing shaft failure evaluation and prediction studies have not comprised any in-depth, comprehensive consideration of positive and negative factors that can influence shaft stability. The importance of human subjective and objective factors requires further exploration, and the study of methods for evaluating predictive models needs to be improved.

To address some of the problems that exist with the study results described above, this paper compiles various research from the perspective of both subjective and objective analysis, with reference to multiple examples of field data, and combines them with the input of many experts' years of work experience. These various data were integrated using the combination weight method, and the comprehensive weight value [25-27] of each factor causing the deformation of mine shafts below thick loose aquifers was calculated. In addition, the degrees of correlation between the influencing factors were determined using fuzzy matter-element analysis theory. Using this approach enabled the effective evaluation of the stability of mine shafts below thick loose aquifers.

\section{Evaluation Methods}

\subsection{Comprehensive Weight Method}

2.1.1. Entropy Weight Method. The entropy weight method [28-31] is an objective analysis method for determining the weight of evaluation indexes. The basic principle is based on the degree of variation between evaluation indexes. If the degree of variation is larger and the information entropy is smaller, the weight of the corresponding index is larger. This method is based on actual geological mining parameters and is conducive to producing more accurate results. If the number of evaluation samples is " $m$ " and the number of evaluation indexes is " $n$," the evaluation matrix can be established as follows:

$$
A=\left[\begin{array}{cccc}
x_{11} & x_{12} & \cdots & x_{1 n} \\
x_{21} & x_{22} & \cdots & x_{2 n} \\
\vdots & \vdots & \vdots & \vdots \\
x_{m 1} & x_{m 2} & \cdots & x_{m n}
\end{array}\right]
$$

\section{(1) Standardization of indexes}

In a multiindex evaluation system, it is not conducive to obtaining accurate results, due to the influence of factors such as the units and the dimensions of each index. Therefore, in order to ensure the reliability of the evaluation results, all evaluation results should undergo a process of standardization.

Standardization of positive indexes is as follows:

$\bar{x}_{i j}=\frac{x_{j}-x_{\min }}{x_{\max }-x_{\min }} \quad(i=1,2, \cdots \cdots, m, j=1,2, \cdots \cdots, n)$.

Standardization of negative indexes is as follows:

$\bar{x}_{i j}=\frac{x_{\max }-x_{j}}{x_{\max }-x_{\min }} \quad(i=1,2, \cdots \cdots, m, j=1,2, \cdots \cdots, n)$.

(2) Weight assignment of each index in the matrix

$$
y_{i j}=\frac{\bar{x}_{i j}}{\sum_{i=1}^{m} \bar{x}_{i j}} \quad(i=1,2, \cdots \cdots, m, j=1,2, \cdots \cdots, n),
$$

where $y_{i j}$ refers to the weight of No. “ $j$ ” evaluation index of No. " $i$ " evaluation sample in the matrix. 


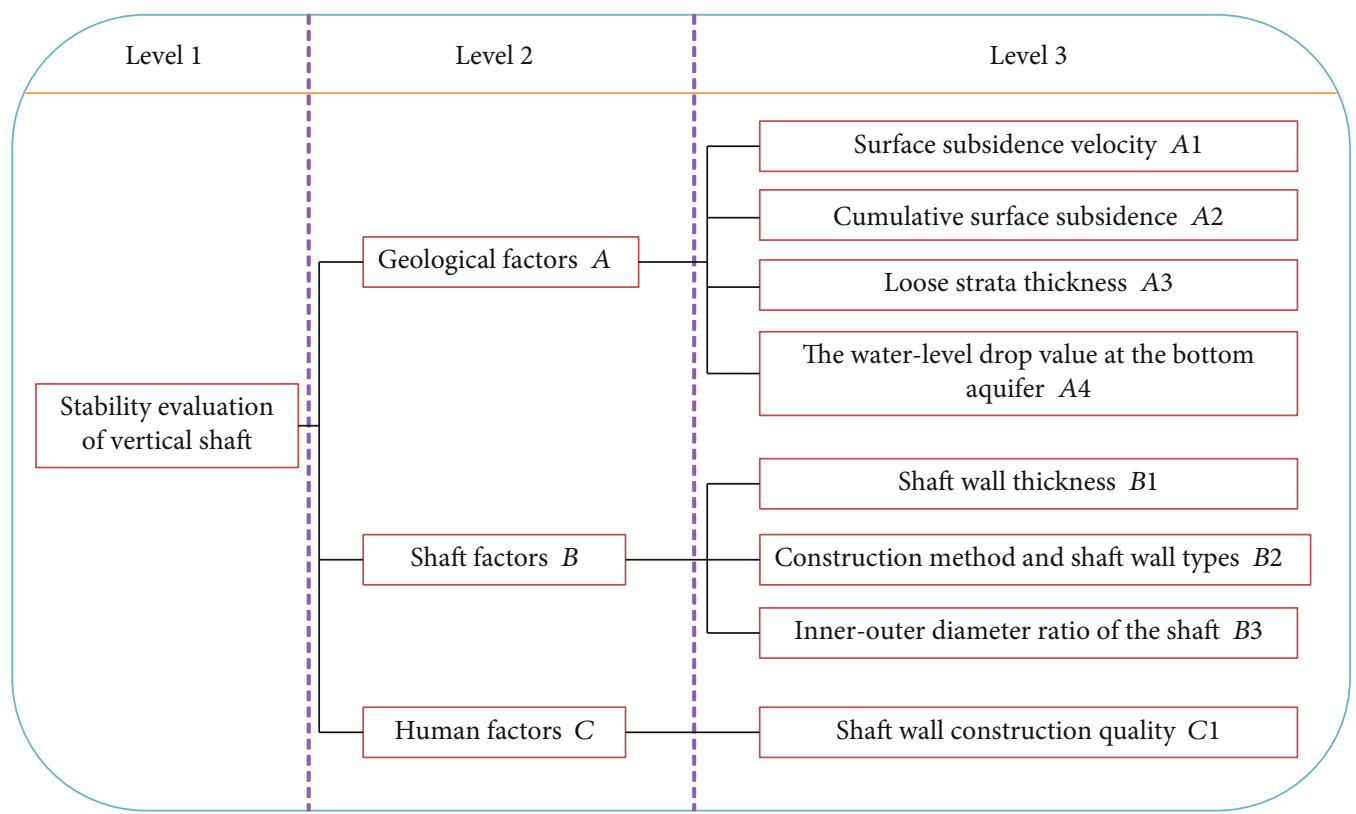

FIGURE 2: A schematic showing the study hierarchy of the AHP method.

(3) Calculate the entropy value of each index

$$
\begin{aligned}
z_{j}=-K \sum_{i=1}^{m}\left(y_{i j} \times \ln y_{i j}\right) & (i=1,2, \cdots \cdots, m, j=1,2, \cdots \cdots, n),
\end{aligned}
$$

where $K$ is a constant value, $K=1 / \ln m$.

(4) Solve the entropy weight of each index

$$
w_{j}=\frac{1-z_{j}}{\sum_{j=1}^{n}\left(1-z_{j}\right)} \quad(j=1,2, \cdots \cdots, n),
$$

where $\sum_{j=1}^{n} w_{j}=1, \omega_{1}=\left(w_{1}, w_{2}, \cdots, w_{n}\right)^{\mathrm{T}}$. From the above equation, it can be determined that the larger the entropy value and the smaller the entropy weight, the lower the degree of importance of the evaluation index.

2.1.2. Analytical Hierarchy Process (AHP) Method. The analytical hierarchy process (AHP) is a subjective analysis method, first proposed by Saaty in the early 1970s, to quantify qualitative factors. It is described as a way to convert intangible factors into numerical values, following which a series of pairwise comparisons can be carried out based on the degree of importance of each influencing factor to calculate the weight of each factor. This method solves the problem of evaluating factors that are difficult to quantify or prioritize [32-34]; the basic steps are as follows:

(1) Establishment of a hierarchical structure system, which can generally be divided into three grades, namely, the target grade, the intermediate classification grade, and the factor layer, as shown in Figure 2
(2) Construction of a judgment matrix. When the weight analysis is carried out for each factor of each grade, two factors are selected to compare their relative scales and determine their grades according to their degrees of importance. For details, please refer to Table 2

(3) Calculation of the weight of each factor. First, the degrees of importance of each grade's influencing factors are quantified then normalized. Second, fixed values of the judgment matrix are obtained, followed by an analysis of the proportion contributed by the degrees of importance of each grade's influencing factors, to obtain each factor's weight value $\omega_{2}=$ $\left(w_{1}^{\prime}, w_{2}^{\prime}, \cdots, w_{n}^{\prime}\right)^{\mathrm{T}}$.

(4) Consistency test. AHP requires that the judgment matrix has a general level of consistency, which can ensure the calculated results are basically reasonable. The calculation formula is as follows:

$$
\begin{aligned}
& R_{c}=\frac{I_{C}}{I_{R}}, \\
& I_{C}=\frac{\lambda_{\max }-n}{n-1},
\end{aligned}
$$

where $R_{c}$ is the consistency ratio, $\lambda_{\max }$ is the maximum eigenvalue of the consistency matrix, $n$ is the number of factors compared in pairs, and $I_{\mathrm{R}}$ is the random consistency index; the value of which is determined according to Table 3.

2.1.3. Combined Weighting Method Based on Game Theory. Subjective and objective weight information in relation to the stability of shafts in areas with thick loose strata were 
TABle 2: Definition of the degree of importance of a factor.

Comparison of the importance of two factors

Corresponding quantized value

Two factors are of equal importance

1

One factor is more important than the other

The importance of one factor is greater than that of the other

The importance of one factor is very large compared to the other factor

The importance of one factor is greater than the other factor

An intermediate value of the above comparison $2,4,6,8$

TABLE 3: Random consistency index value, $I_{R}$.

\begin{tabular}{cccccccccccc}
\hline$n$ & 1 & 2 & 3 & 4 & 5 & 6 & 7 & 8 & 9 & 10 & 11 \\
\hline$I_{\mathrm{R}}$ & 0 & 0 & 0.58 & 0.90 & 1.12 & 1.24 & 1.32 & 1.41 & 1.45 & 1.49 & 1.51 \\
\hline
\end{tabular}

comprehensively analyzed using game theory, so that the calculated results of the comprehensive weighting of the evaluation indexes were comprehensive and scientific. A single weight vector can be expressed as $\omega_{i}=\left(w_{i 1}, w_{i 2}, \cdots, w_{\text {in }}\right)$ $(i=1,2, \cdots, L)$, and the formula of the combined weight method is as follows:

$$
\omega=\sum_{i=1}^{L} \alpha_{i} \cdot \omega_{i}^{T}
$$

Based on the concept of game theory, the coefficient $\alpha_{i}$ was optimized to minimize the variance between the integrated weight vector $\omega$ and the single weight vector $\omega_{i}$, thereby obtaining an ideal weight vector.

$$
\min \quad Z=\left\|\sum_{i=1}^{n} \alpha_{i} \cdot \omega_{i}^{T}-\omega_{i}\right\|_{2} \quad(i=1,2, \cdots, n) .
$$

The coefficient $\alpha_{i}$ obtained was then normalized:

$$
\alpha_{i}^{\prime}=\frac{\left|\alpha_{i}\right|}{\sum_{i=1}^{n} \alpha_{i}}
$$

The integrated weight vector is as follows:

$$
\omega^{\prime}=\sum_{i=1}^{L} \alpha_{i}^{\prime} \cdot \omega_{i}^{T}
$$

2.2. Fuzzy Matter-Element Analysis Method. The concept of Extenics first appeared in a paper published by the Chinese scholar Professor Cai Wen, entitled "Extension set and noncompatible problems". Its theoretical background is in matter-element theory and extension set theory. Through the qualitative analysis of a matter-element, combined with the quantitative calculation of a correlation function, it transforms various indexes that influence the object under evalua- tion into a compatible problem; thus, a comprehensive evaluation model [35-41] that is more in line with objective reality is obtained. The calculation process of the fuzzy matter-element analysis method is as follows:

(1) Determination of the classical field

A matter-element analysis model generally consists of three parts: matter, character, and value. If the number of evaluation indexes is " $n$," it is an $n$-dimensional matter-element model.

$$
\begin{aligned}
R_{0 j} & =\left(N_{0 j}, c_{i}, v_{0 j 1}\right)=\left[\begin{array}{ccc}
N_{0 j} & c_{1} & v_{0 j 1} \\
& c_{2} & v_{0 j 2} \\
& \vdots & \vdots \\
& c_{n} & v_{0 j n}
\end{array}\right] \\
& =\left[\begin{array}{ccc}
N_{0 j} & c_{1} & <a_{0 j 1}, b_{0 j 1}> \\
& c_{2} & <a_{0 j 2}, b_{0 j 2}> \\
\vdots & \vdots \\
c_{n} & <a_{0 j n}, b_{0 j n}>
\end{array}\right],
\end{aligned}
$$

where $R_{0 j}$ is the classical field matter element, $N_{0 j}$ is the $j^{\text {th }}$ stability evaluation grade of the shaft, $c_{n}$ is the $n^{\text {th }}$ index of the evaluation index system, $v_{0 j n}$ is the value range of the $n^{\text {th }}$ evaluation index in the $j^{\text {th }}$ grade, and $a_{0 j n}$ and $b_{0 j n}$, respectively, represent the lower and upper limits of the $v_{0 j n}$ value.

(2) Determination of the segment field

$$
R_{p}=\left(N_{P}, c_{i}, v_{p i}\right)=\left[\begin{array}{ccc}
N_{P} & c_{1} & <a_{p 1}, b_{p 1}> \\
& c_{2} & <a_{p 2}, b_{p 2}> \\
& \vdots & \vdots \\
& c_{n} & <a_{p n}, b_{p n}>
\end{array}\right],
$$

where $R_{p}$ is the classical field matter element, $N_{P}$ is all grades of the shaft stability evaluation, $v_{p i}$ is an extended quantization range of index $c_{i}$, and the variation range is from $a_{p i}$ to $b_{p i}$.

(3) Determination of the matters to be evaluated

The stability evaluation grade of the mine shaft to be evaluated by the matter element is as follows:

$$
R=\left[\begin{array}{ccc}
p & c_{1} & v_{1} \\
& c_{2} & v_{2} \\
& \vdots & \vdots \\
& c_{n} & v_{n}
\end{array}\right]
$$


where $p$ is the object element to be evaluated, $c_{n}$ is the $n^{\text {th }}$ eigenvalue of the $j^{\text {th }}$ grade, and $v_{n}$ is the actual value of the stability evaluation index of the mine shaft to be evaluated.

(4) Calculation of the correlation function

When constructing the correlation function, the concepts of the extension distance and position are introduced to describe the positional relationship between the point and the interval, so that it can express the degrees of certain attributes of the object. The expression is as follows:

$$
\begin{aligned}
K_{j}\left(x_{i}\right)=\left\{\begin{array}{l}
-\frac{\rho\left(x_{i}, X_{j i}\right)}{\left|X_{j i}\right|}\left(x_{i} \in X_{j i}\right), \\
\frac{\rho\left(x_{i}, X_{j i}\right)}{\rho\left(x_{i}, X_{p i}\right)-\rho\left(x_{i}, X_{j i}\right)}\left(x_{i} \notin X_{j i}\right),
\end{array}\right. \\
\rho\left(x_{i}, X_{k i}\right)=\left|x_{i}-\frac{A_{k i}+B_{k i}}{2}\right|-\frac{B_{k i}-A_{k i}}{2} \quad(k=j, p),
\end{aligned}
$$

where $\rho\left(x_{i}, X_{j i}\right)$ is the distance from $x_{i}$ to the classical field interval $\left[A_{j i}, B_{j i}\right], \rho\left(x_{i}, X_{p i}\right)$ is the distance from $x_{i}$ to the segment field interval $\left[A_{p i}, B_{p i}\right]$, and $K_{j}\left(x_{i}\right)$ is the correlation index function.

(5) Calculation of the comprehensive correlation degree

$$
K_{j}(N)=\sum_{i=1}^{n} \omega_{j} K_{j}\left(x_{i}\right)
$$

where $\omega_{j}$ is the weight coefficient of the shaft stability evaluation index and $K_{j}(N)$ is the comprehensive correlation degree of the object to be tested at the $j$ th grade.

(6) Determination of the category and grade variable eigenvalues of the object to be evaluated: if $K_{j 0}(N)=$ $\max K_{j}(N) \quad(j=1,2, \cdots, n)$, then $N$ is evaluated to belong to the category $j 0$ denoted as follows:

$$
\bar{K}_{j}(N)=\frac{K_{j}(p)-\min K_{j}(N)}{\max K_{j}(N)-\min K_{j}(N)} .
$$

Then, the grade variable eigenvalue $J$ of $N$ is as follows:

$$
J=\frac{\sum_{j=1}^{n} j \cdot \overline{K_{j}}(N)}{\sum_{j=1}^{n} \overline{K_{j}}(N)} .
$$

\section{Model Preparation}

3.1. Evaluation Index System and Determination of the Evaluation Grade. Since mine shafts located below thick loose aquifers are subject to the influence of complex geolog- ical mining factors, which may lead to instability and failure, it is undoubtedly very important to establish a standard evaluation index system when studying the degree of stability of shafts. Based on previous study results and field monitoring data of shaft deformations from recent years, it was concluded following comprehensive analysis that the factors affecting shaft instability can be divided into geological factors $(A)$, shaft factors $(B)$, and human factors $(C)$. Geological factors can be further divided into surface subsidence velocity $\left(A_{1}\right)$, cumulative surface subsidence $\left(A_{2}\right)$, loose strata thickness $\left(A_{3}\right)$, and water level drop value at the bottom of a loose aquifer $\left(A_{4}\right)$. Shaft factors can be further divided into shaft wall thickness $\left(B_{1}\right)$, construction method and type of shaft wall $\left(B_{2}\right)$, and the inner-outer diameter ratio of the shaft $\left(B_{3}\right)$. Human factors include the quality of the shaft wall construction $\left(C_{1}\right)$.

(1) Surface subsidence velocity: the surface subsidence velocity reflects the magnitude of the subsidence of the stratum per unit time, which can directly affect the stability of a shaft structure. Under normal circumstances, the greater the surface subsidence velocity, the greater the magnitude of subsidence of the formation, and the greater the stress on the shaft; this is more likely to damage the shaft structure or cause the shaft to be deflected, increasing the likelihood of shaft instability [42, 43]

(2) Cumulative surface subsidence: this can reflect the historical total amount influenced by underground mining and the cumulative ground subsidence (including the amount of cumulative compression of the loose strata). If other factors are kept unchanged, the greater the cumulative surface subsidence, the greater the additional stress applied to a shaft, which is likely to damage the fixed structure of the shaft outer wall, resulting in lower stability of the shaft

(3) Loose strata thickness: loose strata is a type of unsaturated soil composed of three phases, solid, liquid, and gas. Its mechanical properties are extremely complex, and the skeletal structure composed of solids plays a supporting role [44]. Generally speaking, if the loose strata is thicker, the additional stress action (compression) it applies to the shaft is more obvious, and the more likely damage will occur in the shaft at the bottom of the loose section, thus reducing the stability of the shaft

(4) The water level drop value at the bottom of a loose aquifer: the magnitude of any drop in water level at the bottom of a loose aquifer plays a very important role in shaft stability. The change in water content of loose soil has a great influence on that soil's mechanical properties. With a decrease in water level, the sand in an aquifer becomes compacted and consolidated, leading to additional stress being applied to a shaft; this can cause serious damage to the outer wall structure of a shaft at the aquifer, such as 
generating cracks on the shaft wall, and sudden water burst accidents are more likely to occur in this case $[45,46]$

(5) Shaft wall thickness: the shaft wall thickness can effectively bear the asymmetric additional stress generated by the vertical displacement of loose strata, which can protect the shaft. In general, as shaft thickness increases, the resistance of the shaft structure becomes stronger and the stability of the shaft is increased [47]

(6) Construction method and shaft wall types: methods of shaft construction include the freezing method and the drilling method, the latter being more conducive to maintaining shaft stability. Shaft wall types include single-layer shaft walls, double-layer shaft walls, prefabricated shaft walls, and composite shaft walls. The drilling method is used for prefabricated shaft walls, while the freezing method can be adopted for all four shaft wall types. In terms of waterproofing and the ability to resist deformation, the composite shaft wall is the best, followed by the prefabricated shaft wall, then the double-layer shaft wall. In this paper, a comprehensive qualitative analysis of the factors influencing shaft stability was carried out, as shown in Table 4

Among them, it is 0.7 for the single-layer shaft wall and the freezing method, 0.5 for the double-layer shaft wall and the freezing method, 0.3 for the prefabricated shaft wall and the drilling method, and 0.1 for the composite shaft wall and the freezing method.

(7) Inner-outer diameter ratio of the shaft: the larger the outer diameter of a shaft, the greater the contact area with the stratum, and the greater the additional stress applied. The smaller the inner diameter of a shaft, the greater its ability to resist deformation, and the more stable it is. So, it is more convincing to use the innerouter diameter ratio of the shaft as an influencing factor. If the inner-outer diameter ratio of a shaft is larger, the shaft's stability is lower, as is its ability to resist deformation and its waterproof effectiveness

(8) Shaft wall construction quality: the construction quality of a shaft wall is an important factor affecting the quality of a shaft and represents a human factor. In order to highlight the importance of construction quality on shaft stability, a qualitative analysis was performed, combined with the situations of previous field examples, as shown in Table 5

There have been few studies on the degree of deformation and damage to shafts, so until now, there has been no clear qualitative division between the levels of damage. Based on many years' monitoring data of the postmining deformation of shafts below thick loose strata, together with the results of relevant studies, we categorized the stability of shafts below thick loose aquifers into five grades, following a comprehensive consideration of variations in a number of factors. These
TABLE 4: Influencing effect assignment of the construction method and shaft wall type.

\begin{tabular}{lccccc}
\hline $\begin{array}{l}\text { Construction } \\
\text { method and } \\
\text { shaft lining } \\
\text { type }\end{array}$ & Safe & Safer & $\begin{array}{c}\text { Critically } \\
\text { safe }\end{array}$ & Dangerous & $\begin{array}{c}\text { Extremely } \\
\text { dangerous }\end{array}$ \\
\hline Assignment & $0 \sim 0.2$ & $0.2 \sim 0.4$ & $0.4 \sim 0.6$ & $0.6 \sim 0.8$ & $0.8 \sim 1$ \\
\hline
\end{tabular}

TABLE 5: Effect assignment of the shaft wall construction quality.

\begin{tabular}{lccccc}
\hline $\begin{array}{l}\text { Shaft wall } \\
\text { construction } \\
\text { quality grade }\end{array}$ & Safe Safer & $\begin{array}{c}\text { Critically } \\
\text { safe }\end{array}$ & Dangerous & $\begin{array}{c}\text { Extremely } \\
\text { dangerous }\end{array}$ \\
\hline Assignment & $0 \sim 2$ & $2 \sim 4$ & $4 \sim 6$ & $6 \sim 8$ & $8 \sim 10$ \\
\hline
\end{tabular}

grades are outlined as follows. Grade I refers to new shafts that have just been put into production and have very low deformation values; the stability of such shafts is defined as being safe. Grade II shafts are defined as having small deformations due to influencing factors and undamaged shaft wall surfaces; the stability of such shafts is also defined as being safe. Grade III shafts are those shafts in which deflection or instability has occurred but which have been repaired in a timely manner; they belong to the critical safety grade. Grade IV includes shafts in which instability has occurred and the shaft wall has been affected to a certain extent, but the fracture height and depth are less than $1 \mathrm{~m}$ and $100 \mathrm{~mm}$, respectively; these shafts belong to the dangerous grade. Grade V shafts are shafts in which instability has occurred, large pieces of concrete have fallen from the shaft walls, and the depth of the damage is more than $100 \mathrm{~mm}$; these shafts are classified as extremely dangerous.

At the same time, with reference to relevant scholars' analyses of shaft deformation and shaft stability evaluation, and geological parameter monitoring results from occasions when shaft instability has occurred, we performed a standard range classification of the parameter values according to the abovementioned shaft stability grade classification (Table 6). This is more conducive to the evaluation of shaft failure in areas with thick loose strata, and provides safe and reliable guidance for the prediction and prevention of shaft failure when mining coal seams below thick loose strata.

3.2. Model Research Process. Figure 3 displays the present research process. First, the corresponding weight vectors of various evaluation indexes were calculated using the entropy weight method and AHP. Next, coefficient optimization was conducted on the weight vectors by means of the combination weight method and comprehensive weight vectors under both subjective and objective conditions were obtained. Finally, the comprehensive weight vectors were substituted into fuzzy matter-element model to calculate the evaluation grades of different shafts.

3.3. Selection of the Example Data. Mines where shaft rupture accidents have occurred in East China are generally covered by thick loose strata or very thick loose strata. In view of the large differences between the mechanisms and 
TABLE 6: Standard range of stability evaluation indexes of shafts below thick loose strata.

\begin{tabular}{llccccc}
\hline Evaluation index & Indicator type & Safe & Safer & Critically safe & Dangerous & Extremely dangerous \\
\hline$A_{1}$ & Positive indicator & $0 \sim 14$ & $14 \sim 28$ & $28 \sim 42$ & $42 \sim 56$ & $56 \sim 70$ \\
$A_{2}$ & Positive indicator & $0 \sim 110$ & $110 \sim 220$ & $220 \sim 330$ & $330 \sim 440$ & $440 \sim 550$ \\
$A_{3}$ & Positive indicator & $0 \sim 125$ & $125 \sim 250$ & $250 \sim 375$ & $375 \sim 500$ & $500 \sim 625$ \\
$A_{4}$ & Positive indicator & $0 \sim 16$ & $16 \sim 32$ & $32 \sim 48$ & $48 \sim 64$ & $64 \sim 80$ \\
$B_{1}$ & Negative indicator & $1.6 \sim 1.9$ & $1.3 \sim 1.6$ & $1.0 \sim 1.3$ & $0.7 \sim 1.0$ & $0.6 \sim 0.8$ \\
$B_{2}$ & Positive indicator & $0 \sim 0.2$ & $0.2 \sim 0.4$ & $0.4 \sim 0.6$ & $0.4 \sim 0.7$ \\
$B_{3}$ & Positive indicator & $0.6 \sim 0.65$ & $0.65 \sim 0.7$ & $0.7 \sim 0.75$ & $0.75 \sim 0.8$ & $0.8 \sim 1$ \\
$B_{4}$ & Positive indicator & $0 \sim 2$ & $2 \sim 4$ & $4 \sim 6$ & $6 \sim 8$ & $0.8 \sim 0.85$ \\
\hline
\end{tabular}

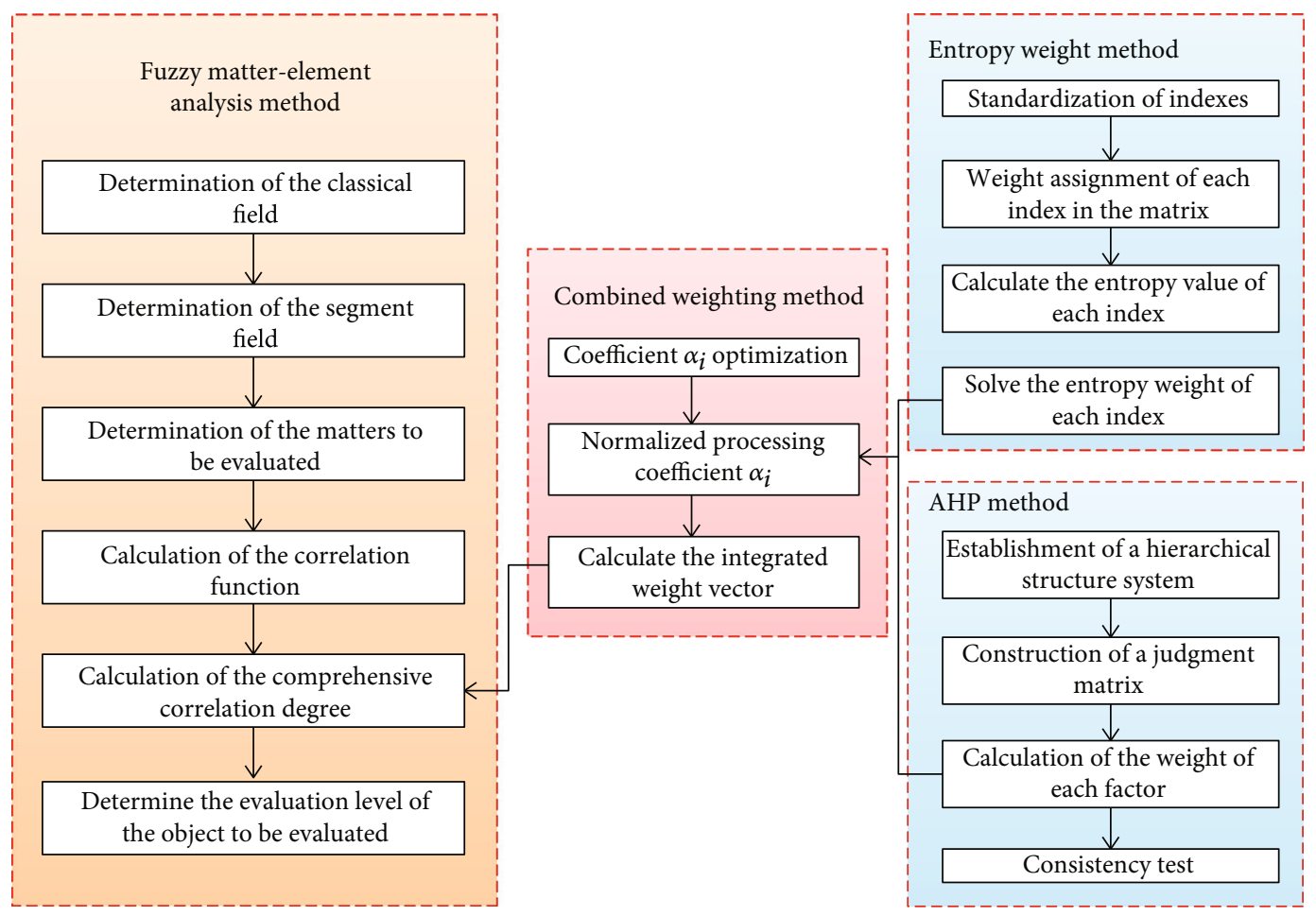

Figure 3: Fuzzy matter-element analysis model flow chart.

phenomena of mine shaft failures under thick loose strata compared with those under very thick loose strata, this paper focuses on analyzing the influence of thick loose strata on the stability of mine shafts. This will help to ensure that the evaluation model we have established is more representative and appropriate (the influence of very thick loose strata on the stability of mine shafts below them will be investigated in future work). Taking the four mining regions of Huaibei, Huainan, Xuzhou, and Zhangzhou as examples, the parameters of factors influencing typical mine shafts were selected for comprehensive analysis (please see Table 7 for details).

\section{Model Calculation Results}

\subsection{The Process of Calculation Using the Comprehensive Weight Method}

4.1.1. Evaluation Indexes Affecting Shaft Stability when Calculated by the Entropy Weight Method. Many different shaft instability phenomena occur in mines in East China; therefore, we collected geological data with distinctive characteristics from each mining area (Table 7) and calculated the factors influencing shafts using the entropy weight method to determine the major factors that affected shaft stability.

First, the indicated value of each influencing factor was determined. The indicated value of the positive index was 1 and that of the negative index was 0 . The indicated value of each influencing factor is shown in Table 8.

The parameters of each index were standardized with reference to the values indicated above. Equations (8), (9), (10), (11) and (12) were then coded using MATLAB software. The original geological parameters collected were substituted, and the indicated values were used to calculate the results. Finally, entropy values and entropy weights for each index were obtained, as shown in Table 9.

It can be seen from Table 9 that the water level drop value at the bottom of a loose aquifer has the largest weight value, followed by surface subsidence velocity, loose strata 


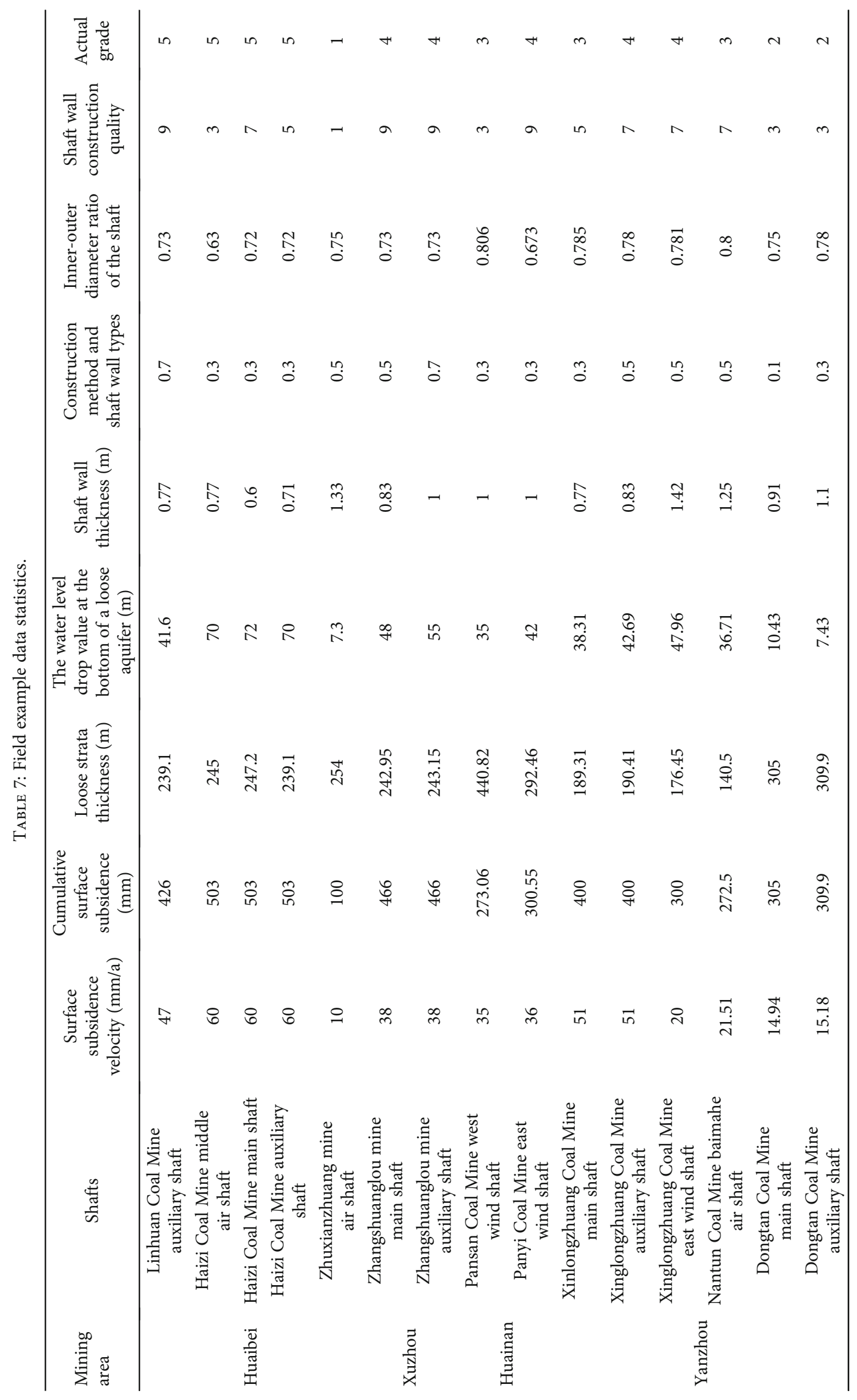


TABLE 8: Index value of each factor influencing shaft stability.

\begin{tabular}{lc}
\hline Evaluation index & Indicated value \\
\hline Surface subsidence velocity $(\mathrm{mm} / \mathrm{a})$ & 1 \\
Cumulative surface subsidence $(\mathrm{mm})$ & 1 \\
Loose strata thickness $(\mathrm{m})$ & 1 \\
The water level drop value at the bottom of & 1 \\
a loose aquifer (m) & 0 \\
Shaft wall thickness $(\mathrm{m})$ & 1 \\
Construction method and shaft wall types & 1 \\
Inner-outer diameter ratio of the shaft & 1 \\
Shaft wall construction quality & \\
\hline
\end{tabular}

TABLE 9: Calculated results of various influencing factors.

\begin{tabular}{|c|c|c|c|}
\hline Evaluation index & $\begin{array}{l}\text { Entropy } \\
\text { value }\end{array}$ & $\begin{array}{l}\text { Entropy } \\
\text { weight }\end{array}$ & Ranking \\
\hline Surface subsidence velocity $(\mathrm{mm} / \mathrm{a})$ & 0.9111 & 0.1687 & 2 \\
\hline $\begin{array}{l}\text { Cumulative surface subsidence } \\
(\mathrm{mm})\end{array}$ & 0.9569 & 0.0818 & 8 \\
\hline Loose strata thickness (m) & 0.9256 & 0.1411 & 3 \\
\hline $\begin{array}{l}\text { The water level drop value at the } \\
\text { bottom of a loose aquifer }(\mathrm{m})\end{array}$ & 0.9099 & 0.1709 & 1 \\
\hline Shaft wall thickness (m) & 0.9397 & 0.1144 & 5 \\
\hline $\begin{array}{l}\text { Construction method and shaft } \\
\text { wall types }\end{array}$ & 0.9407 & 0.1125 & 6 \\
\hline $\begin{array}{l}\text { Inner-outer diameter ratio of the } \\
\text { shaft }\end{array}$ & 0.9569 & 0.0818 & 7 \\
\hline Shaft wall construction quality & 0.9321 & 0.1288 & 4 \\
\hline
\end{tabular}

thickness, shaft wall construction quality, shaft wall thickness, construction method, and shaft type, with the cumulative surface subsidence and the inner-outer diameter ratio of the shaft weighted least. The total weighting of the first six influencing factors is 0.8364 , which means they play a decisive role in the stability of shafts below thick loose aquifers. Therefore, an in-depth study of these leading factors that influence shaft stability will help prevent and control shaft failure when mining coal seams located below thick loose aquifers.

4.1.2. Evaluation Indexes Affecting Shaft Stability when Calculated by the AHP Method. The AHP method was used to qualitatively analyze evaluation indexes affecting shaft stability from a subjective perspective. By combining these findings with the empirical analyses of factors affecting the shaft stability reported by many experts and scholars, the degree of importance of each index was calculated and ranked.

First, based on the opinions of various experts, the results of their analyses of each influencing factor were summarized, and a judgment matrix was constructed according to the grades (please see Tables 10-13 for details).

4.1.3. Evaluation Indexes Affecting Shaft Stability when Calculated by the Combined Weight Method. Based on the concept and theoretical method of game theory, the results calculated using the subjective weight method and
TABLE 10: Establishment of the Grade I judgment matrix.

\begin{tabular}{ccccc}
\hline$O$ & $A$ & $B$ & $C$ & Eigenvector \\
\hline$A$ & 1 & $7 / 4$ & $9 / 2$ & 0.5575 \\
$B$ & $4 / 7$ & 1 & $18 / 7$ & 0.3186 \\
$C$ & $2 / 9$ & $7 / 18$ & 1 & 0.1239 \\
\hline
\end{tabular}

Consistency test of the first-order judgment matrix: $n=3, \lambda_{\max }=3, R_{c}=$ $0.000086<0.1$; this meets the consistency requirements.

TABle 11: Establishment of Grade II judgment matrix $A-A_{n}$.

\begin{tabular}{cccccc}
\hline$A$ & $A_{4}$ & $A_{2}$ & $A_{3}$ & $A_{1}$ & Eigenvector \\
\hline$A_{4}$ & 1 & 2 & $3 / 2$ & $6 / 5$ & 0.3331 \\
$A_{2}$ & $1 / 2$ & 1 & $3 / 4$ & $3 / 5$ & 0.1671 \\
$A_{3}$ & $2 / 3$ & $4 / 3$ & 1 & $4 / 5$ & 0.2221 \\
$A_{1}$ & $5 / 6$ & $5 / 3$ & $5 / 4$ & 1 & 0.2777 \\
\hline
\end{tabular}

Consistency test of the second-order judgment matrix: $n=4, \lambda_{\max }=3.99991$, $R_{\mathrm{c}}=-0.000033<0.1$; this meets the consistency requirements.

TABLE 12: Establishment of Grade II judgment matrix $B-B_{n}$.

\begin{tabular}{lcccc}
\hline$B$ & $B_{1}$ & $B_{2}$ & $B_{3}$ & Eigenvector \\
\hline$B_{1}$ & 1 & 1 & $3 / 2$ & 0.375 \\
$B_{2}$ & 1 & 1 & $3 / 2$ & 0.375 \\
$B_{3}$ & $2 / 3$ & $2 / 3$ & 1 & 0.25 \\
\hline \\
Consistency test of the second-order judgment matrix: $n=3, \lambda_{\max }=0$, \\
$R_{\mathrm{c}}=-2.5862<0.1 ;$ this meets the consistency requirements.
\end{tabular}

$R_{c}=-2.5862<0.1 ;$ this meets the consistency requirements.

TABLE 13: Total weight calculation for each evaluation index.

\begin{tabular}{ccccc}
\hline & $A(0.5575)$ & $B(0.3186)$ & $C(0.1239)$ & Total weighting \\
\hline$A_{1}$ & 0.2777 & 0 & 0 & 0.1548 \\
$A_{2}$ & 0.1671 & 0 & 0 & 0.0932 \\
$A_{3}$ & 0.2221 & 0 & 0 & 0.1238 \\
$A_{4}$ & 0.3331 & 0 & 0 & 0.1857 \\
$B_{1}$ & 0 & 0.375 & 0 & 0.1195 \\
$B_{2}$ & 0 & 0.375 & 0 & 0.1195 \\
$B_{3}$ & 0 & 0.25 & 0 & 0.0797 \\
$C_{1}$ & 0 & 0 & 1 & 0.1239 \\
\hline
\end{tabular}

Total ranking consistency test: $I_{c}=-0.4779, I_{\mathrm{R}}=0.6865, R_{c}=-0.6961<0.1$; this meets the consistency requirements.

the objective weight method were substituted into Equations (9), (10), (11) and (12), and the weight coefficients $\alpha_{1}=0.1828$ and $\alpha_{2}=0.8172$ were determined. Finally, the comprehensive weight value, $\omega^{\prime}$, was calculated (please see Figure 3 for the results).

It can be seen from Figure 4 that the weights of the influencing factors were 0.1826 for the water level drop at the bottom of a loose aquifer, 0.1576 for the surface subsidence velocity, 0.1273 for the loose strata thickness, 0.1249 for the shaft wall construction quality, 0.1185 for the shaft wall thickness, and 0.1181 for the construction method and shaft wall type. The total weighting of these six influencing factors was 0.829 , so they can be used to effectively analyze 


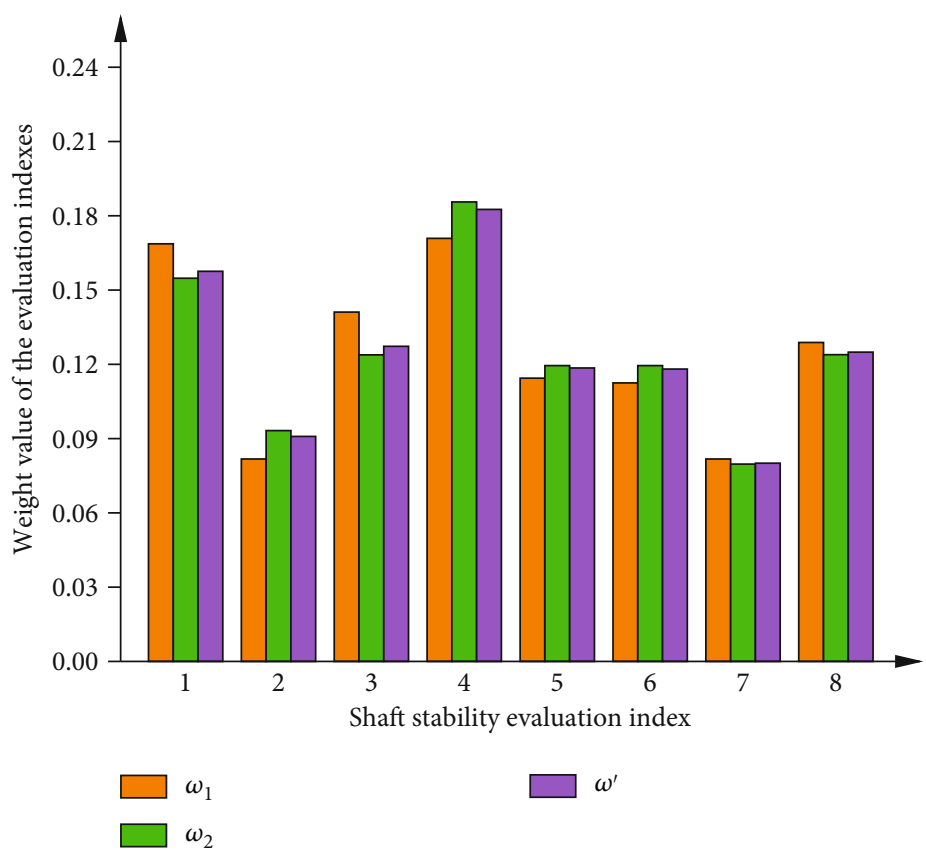

FIGURE 4: Comprehensive weight value of each evaluation index.

TABLE 14: Summary table showing the classical field and segment field values for the evaluation of the stability of shafts below thick loose aquifers.

\begin{tabular}{|c|c|c|c|c|c|c|}
\hline \multirow{2}{*}{ Evaluation index } & \multicolumn{5}{|c|}{ Range of classical field values } & \multirow{2}{*}{ Range of segment field values } \\
\hline & $\mathrm{I}$ & II & III & IV & V & \\
\hline$A_{1}$ & $0 \sim 12$ & $12 \sim 24$ & $24 \sim 36$ & $36 \sim 48$ & $48 \sim 60$ & $0 \sim 60$ \\
\hline$A_{2}$ & $0 \sim 101$ & $101 \sim 202$ & $202 \sim 303$ & $303 \sim 404$ & $404 \sim 505$ & $0 \sim 550$ \\
\hline$A_{3}$ & $0 \sim 88$ & $88 \sim 176$ & $176 \sim 264$ & $264 \sim 352$ & $352 \sim 440$ & $0 \sim 625$ \\
\hline$A_{4}$ & $0 \sim 15$ & $15 \sim 30$ & $30 \sim 45$ & $45 \sim 60$ & $60 \sim 75$ & $0 \sim 80$ \\
\hline$B_{1}$ & $1.6 \sim 1.9$ & $1.3 \sim 1.6$ & $1.0 \sim 1.3$ & $0.7 \sim 1.0$ & $0.4 \sim 0.7$ & $0.4 \sim 1.9$ \\
\hline$B_{2}$ & $0 \sim 0.2$ & $0.2 \sim 0.4$ & $0.4 \sim 0.6$ & $0.6 \sim 0.8$ & $0.8 \sim 1$ & $0 \sim 1$ \\
\hline$B_{3}$ & $0.6 \sim 0.65$ & $0.65 \sim 0.7$ & $0.7 \sim 0.75$ & $0.75 \sim 0.8$ & $0.8 \sim 0.85$ & $0.6 \sim 0.85$ \\
\hline$C_{1}$ & $0 \sim 2$ & $2 \sim 4$ & $4 \sim 6$ & $6 \sim 8$ & $8 \sim 10$ & $0 \sim 10$ \\
\hline
\end{tabular}

and evaluate the stability of shafts below thick loose aquifers. The comprehensive weight method can reasonably summarize the results of the statistical analysis carried out using the entropy weight method and the AHP method. This means it can more effectively interpret the actual situation of shaft stability under both subjective and objective conditions, and help to reliably rank the degrees of importance of each influencing factor. Thus, the leading factors affecting shaft deformation were explored, providing a reference for reducing shaft deformation and controlling it within a safe range.

4.2. Fuzzy Matter-Element Analysis Process Calculation. On the basis of the established evaluation index system and evaluation grades, and after the weight of each influencing factor was determined by the comprehensive weight method, further comprehensive evaluation and analysis of the stability of shafts below thick loose aquifers was carried out. The specific calculation procedures were as follows:
(1) According to the evaluation index standard range for the stability of shafts below thick loose strata (Table 6), the classical field and the segment field were constructed as shown in Table 14

(2) Calculation of the degree of correlation. In this paper, we chose the auxiliary shaft of Linhuan Coal Mine as an example. With reference to Table 14 and combined with Equations (16) and (17), five grades of correlation degree of the eight evaluation indexes were calculated. Then, the actual category of each index was determined, as shown in Table 15

(3) Calculation of the comprehensive degree of correlation and determination of the stability grade that each shaft belongs to the following:

From the results of the calculation shown in Table 16, it can be seen that by using a comprehensive analysis based on the comprehensive weight method and the matterelement analysis model, the actual situations in fifteen mine 
TABle 15: Degrees of correlation of stability evaluation indexes of the auxiliary shaft of Linhuan Coal Mine.

\begin{tabular}{lcccccc}
\hline Correlation degree of each evaluation index & I & II & III & IV & V & Category \\
\hline$A_{1}$ & -0.7292 & -0.6389 & -0.4583 & 0.0833 & -0.0714 & IV \\
$A_{2}$ & -0.8045 & -0.7393 & -0.6089 & -0.2178 & 0.2178 & V \\
$A_{3}$ & -0.4293 & -0.2390 & 0.2830 & -0.1103 & -0.3598 & III \\
$A_{4}$ & -0.4433 & -0.2578 & 0.2267 & -0.0924 & -0.3552 & III \\
$B_{1}$ & -0.6917 & -0.5889 & -0.3833 & 0.2333 & -0.1591 & IV \\
$B_{2}$ & -0.6250 & -0.5000 & -0.2500 & 0.5000 & -0.2500 & IV \\
$B_{3}$ & -0.4000 & -0.2000 & 0.4000 & -0.1429 & -0.3684 & III \\
$C_{1}$ & -0.8750 & -0.8333 & -0.7500 & -0.5000 & 0.5000 & V \\
$K_{1}(x)$ & -0.6207 & -0.4943 & -0.1868 & -0.0248 & -0.1176 & IV \\
\hline
\end{tabular}

TABLE 16: List of stability evaluation results for each shaft.

\begin{tabular}{|c|c|c|c|c|c|c|c|c|c|c|}
\hline Shafts & $K\left(x_{1}\right)$ & $K\left(x_{2}\right)$ & $K\left(x_{3}\right)$ & $K\left(x_{4}\right)$ & $K\left(x_{5}\right)$ & $\begin{array}{c}\text { Entropy weight } \\
\text { method }\end{array}$ & $\begin{array}{c}\text { AHP } \\
\text { method }\end{array}$ & Category & $\begin{array}{l}\text { Category } \\
\text { eigenvalue }\end{array}$ & $\begin{array}{c}\text { Actual } \\
\text { category }\end{array}$ \\
\hline $\begin{array}{l}\text { Linhuan Coal Mine auxiliary } \\
\text { shaft }\end{array}$ & -0.6207 & -0.4943 & -0.1868 & -0.0248 & -0.1176 & $\mathrm{IV}^{* *}$ & $\mathrm{IV}^{* *}$ & $\mathrm{IV}^{* *}$ & 10.8304 & $\mathrm{~V}$ \\
\hline $\begin{array}{l}\text { Haizi Coal Mine middle air } \\
\text { shaft }\end{array}$ & -0.5829 & -0.4238 & -0.5345 & -0.5377 & -0.2212 & $\mathrm{~V}$ & $\mathrm{~V}$ & $\mathrm{~V}$ & 6.7811 & $\mathrm{~V}$ \\
\hline Haizi Coal Mine main shaft & -0.7149 & -0.5597 & -0.4953 & -0.4551 & -0.1041 & $\mathrm{~V}$ & $\mathrm{~V}$ & $\mathrm{~V}$ & 8.2883 & $\mathrm{~V}$ \\
\hline Haizi Coal Mine auxiliary shaft & -0.6638 & -0.4915 & -0.3561 & -0.4744 & -0.1395 & $\mathrm{~V}$ & $\mathrm{~V}$ & $\mathrm{~V}$ & 8.8635 & $\mathrm{~V}$ \\
\hline Zhuxianzhuang mine air shaft & -0.0040 & -0.2555 & -0.3021 & -0.5014 & -0.6400 & I & I & I & 4.6743 & I \\
\hline $\begin{array}{l}\text { Zhangshuanglou mine main } \\
\text { shaft }\end{array}$ & -0.5856 & -0.4475 & -0.1105 & -0.0475 & -0.1545 & IV & IV & IV & 11.1682 & IV \\
\hline $\begin{array}{l}\text { Zhangshuanglou mine } \\
\text { auxiliary shaft }\end{array}$ & -0.5984 & -0.4646 & -0.1657 & -0.0200 & -0.1517 & IV & IV & IV & 10.5686 & IV \\
\hline $\begin{array}{l}\text { Pansan Coal Mine western } \\
\text { wind shaft }\end{array}$ & -0.4904 & -0.1942 & -0.1320 & -0.3154 & -0.3446 & III & III & III & 8.6396 & III \\
\hline $\begin{array}{l}\text { Panyi Coal Mine eastern wind } \\
\text { shaft }\end{array}$ & -0.5001 & -0.2387 & -0.1389 & -0.1333 & -0.2848 & IV & $\mathrm{III}^{* *}$ & IV & 11.3147 & IV \\
\hline $\begin{array}{l}\text { Xinlongzhuang Coal Mine } \\
\text { main shaft }\end{array}$ & -0.5230 & -0.2966 & -0.0820 & -0.1282 & -0.2451 & III & III & III & 10.7584 & III \\
\hline $\begin{array}{l}\text { Xinglongzhuang Coal Mine } \\
\text { auxiliary shaft }\end{array}$ & -0.5746 & -0.4248 & -0.1230 & 0.0427 & -0.2069 & IV & IV & IV & 9.6585 & IV \\
\hline $\begin{array}{l}\text { Xinglongzhuang Coal Mine } \\
\text { eastern wind shaft }\end{array}$ & -0.4398 & -0.1281 & -0.0616 & -0.0596 & -0.4062 & $\mathrm{~V}^{* *}$ & IV & IV & 9.0658 & IV \\
\hline $\begin{array}{l}\text { Nantun Coal Mine baimahe air } \\
\text { shaft }\end{array}$ & -0.4133 & -0.1093 & 0.0746 & -0.1573 & -0.3970 & III & III & III & 6.5114 & III \\
\hline Dongtan Coal Mine main shaft & -0.1750 & -0.1848 & -0.3467 & -0.2967 & -0.5650 & $\mathrm{I}^{* *}$ & $\mathrm{I}^{* *}$ & $\mathrm{I}^{* *}$ & 7.3814 & II \\
\hline $\begin{array}{l}\text { Dongtan Coal Mine auxiliary } \\
\text { shaft }\end{array}$ & -0.2263 & -0.0949 & -0.2769 & -0.2808 & -0.5412 & II & II & II & 6.8164 & II \\
\hline
\end{tabular}

shafts could be compared, and the evaluated safety grades of thirteen of these shafts were correctly judged, giving a judgment accuracy of $86.67 \%$. The comprehensive analysis results of 15 mine shafts using the entropy weight method and fuzzy matter-element analysis model were compared with the actual conditions. In terms of the shaft safety and stability evaluation grade, 12 shafts were accurately judged, with a judgement accuracy of $80 \%$. The comprehensive analysis results of 15 mine shafts using the AHP and the fuzzy matter-element analysis model were also compared with the actual results. The evaluation grades based on the shaft safety and stability of 12 shafts were accurately identified, with a judgment accuracy of $80 \%$. The combination of the comprehensive weighting method and the fuzzy matterelement analysis model was superior to the other two evaluation models in terms of identification accuracy, i.e., it can truly reflect the stability of a vertical shaft below a thick loose aquifer.

For shafts where a Class IV or V failure occurred, the surface subsidence velocity and the water level drop value at the 
bottom of a loose aquifer were larger than those of other shafts: the surface subsidence velocity was generally greater than $36 \mathrm{~mm} / \mathrm{a}$, and the water level drop value at the bottom of a loose aquifer was greater than $45 \mathrm{~m}$. Some shafts were heavily influenced by the shaft wall construction quality, which led to misjudgment.

Above all, the shaft safety and stability evaluation model established by using the comprehensive weight method and the fuzzy matter-element analysis method showed good reliability, and can be used to predict the deformation of mine shafts in regions of East China where there are overlying thick loose strata. This will be beneficial for the judgment of stability and failure prevention in mine shafts in these regions.

The misjudgment of the auxiliary shaft of Linhuan Coal Mine and the main shaft of Dongtan Coal Mine in this analysis may be due to the following reasons: (1) since there are relatively few statistical cases of mine shaft accidents, the matter-element analysis model established still needs to be improved; (2) the evaluation index standard range (Table 6), established with reference to the results of previous studies and field experience, is not sufficiently accurate and needs further refinement.

\section{Conclusions and Prospects}

5.1. Main Conclusions. In this paper, the comprehensive weight method and the fuzzy matter-element analysis method were used to analyze the main factors influencing the stability of shafts below thick loose aquifers, and an analysis model for determining a shaft stability evaluation grade was established. This method provided a novel way to quantitatively evaluate the stability of shafts below the thick loose strata of the Huaihe River and Jining regions, and has important practical significance and safety benefits. The main conclusions are as follows:

(1) The combined weight method based on game theory was used to rationally distribute the weights of the evaluation indexes obtained using the entropy weight method and the AHP method. This avoided the objective influence of a single geological condition and reduced the influence of subjective factors, thus enabling a more scientific and accurate conclusion to be drawn

(2) The ranking of various influencing factors obtained by the combined weight method was as follows: water level drop value at the bottom of a loose aquifer, surface subsidence velocity, loose strata thickness, shaft wall construction quality, shaft wall thickness, construction method and shaft wall type, cumulative surface subsidence, and the inner-outer diameter ratio of a shaft

(3) The matter-element analysis model constructed in this paper showed good reliability and can provide scientific reference values for the prediction and analysis of the stability of mine shafts below thick loose strata in the Huaihe River and Jining regions

\subsection{Prospects}

(1) The matter-element analysis model was based on existing sample data, so the shaft stability evaluation index standard may not reflect the same factors that influence single large deformations of shafts in some mining areas, which may have an influence on the final evaluation results

(2) The thick loose strata in the Huaihe River and Jining regions are composed of Quaternary strata, whereas the thick loose strata in Juye Coal Mine in the Heze region is composed of Quaternary and Neogene strata and has a thickness of about 550 to $850 \mathrm{~m}$. Shaft failures in different regions have their own particular characteristics. In the future, studies into such failures in different regions should be carried out to expand the compatibility and accuracy of the matter-element analysis model described in this paper

(3) In view of the complexity of evaluating the stability of shafts below thick loose aquifers, more example field data should be collected to further study the actions and mechanisms of the factors influencing the stability of shafts below thick loose aquifers, thus improving the accuracy of the model's predictions and judgments

\section{Data Availability}

All data, models, or codes generated or used during the study are available from the corresponding author by request.

\section{Conflicts of Interest}

The authors declare no conflicts of interest.

\section{Acknowledgments}

The authors of the paper would like to extend grateful thanks to the National Natural Science Foundation of China (51774199) for its support, the Haizi Coal Mine of Huaibei Mining Group, the Linhuan Coal Mine, Zhuxianzhuang Coal Mine, and Zhangshuanglou Coal Mine of Xuzhou Mining Group, the Pansan Coal Mine and Panyi Coal Mine of Huainan Mining Group, and the Xinglongzhuang Coal Mine, Nantun Coal Mine, and Dongtan Coal Mine of Yankuang Group Co., Ltd. for providing relevant shaft failure data, and also my senior university fellow Zhu Xianxiang for his suggestions on how to improve this paper.

\section{References}

[1] B. B. Yang and W. P. Guo, "Study on Safety Partition Method of Coal Seam Mining Under Unconsolidated Aquifer," Coal Science and Technology, vol. 40, no. 7, pp. 96-98, 2012.

[2] Q. Wu, Y. Wang, D. K. Zhao, and J. J. Shen, "Water abundance assessment method and application of loose aquifer based on sedimentary characteristics," Journal of China University of Mining \& Technology, vol. 46, no. 3, pp. 460-466, 2017. 
[3] D. M. Yang, W. B. Guo, Y. Tan, and R. H. Bai, "On the fully mechanized cave-in mining safety under the condition of the thin overlain bedrock by the thick alluvium," Journal of Safety and Environment, vol. 18, no. 1, pp. 129-134, 2018.

[4] G. J. Sun, W. Q. Zhang, G. B. Zhang, G. F. Li, and S. X. Xu, "Analysis of the soil structure characteristics of deep and thick unconsolidated layers and feasibility of fully mechanized caving face's improving mining limit," Journal of Anhui University of Science and Technology (Natural Science), vol. 34, no. 4, pp. 10-14, 2014.

[5] J. Shao, F. Zhou, and W. Sun, "Evolution Model of Seepage Characteristics in the Process of Water Inrush in Faults," Geofluids, vol. 2019, Article ID 4926768, 14 pages, 2019.

[6] C. W. Wang, The Research of Auxiliary Shaft's Failure Mechanism and Deformation, Anhui University of Science and Technology, China, 2015.

[7] H. Wang, Research on the Rupture Mechanism of Shaft Lining and Treatment Technology of the Auxiliary Shaft Wall in Wugou Mine, Anhui University of Science and Technology, China, 2015.

[8] Q. J. Yao, Calculation of Aquifer Parameters and Analysis of the Mechanism of Shaft Settlement and Deflection in GuoTun Mine, Anhui University of Science and Technology, China, 2017.

[9] M. Fraštia, M. Plakinger, and J. Beck, "Photogrammetric observation of deformation of the vertical mining shaft," Acta Montanistica Slovaca, vol. 16, no. 4, pp. 276-286, 2011.

[10] W. P. Li, Engineering Geological Research on Coal Mine Shaft Fracture in Deep Topsoil, China University of Mining and Technology Press, XuZhou, China, 2000.

[11] C. Y. Zhang, "Discussion on the monitoring method of the prevention shaft equipment damage and deformation," Shandong Coal Science and Technology, no. 3, pp. 188-190, 2016.

[12] Y. Xu, Y. Luo, J. Li, K. Li, and X. Cao, "Water and sand inrush during mining under thick unconsolidated layers and thin bedrock in the Zhaogu no. 1 coal mine, China," Mine Water and the Environment, vol. 37, no. 2, pp. 336-345, 2018.

[13] B. Rabi, R. Naik Sripad, S. Vijay, K. Sudhakar, and A. Mishra, "Stability analysis of shafts in the proposed deepening in Zawar mines, HZL: a case study," in Proceedings of the conference on Recent Advances in Rock Engineering (RARE 2016), vol. 91, pp. 484-491, Bengaluru, India, 2016.

[14] G. Zhang, K. Zhang, L. Wang, and Y. Wu, "Mechanism of water inrush and quicksand movement induced by a borehole and measures for prevention and remediation," Bulletin of Engineering Geology and the Environment, vol. 74, no. 4, pp. 1395-1405, 2015.

[15] C. Fangpeng, W. Qiang, Z. Shuai, W. Ningan, and J. Yuan, "Damage Characteristics and Mechanism of a Strong Water Inrush Disaster at the Wangjialing Coal Mine, Shanxi Province, China," Geofluids, vol. 2018, Article ID 3253641, 11 pages, 2018.

[16] D. W. Zhou, K. Wu, L. Li, and J. W. Yu, "Impact of thick alluvial soil on a fractured water-conducting zone: an example from Huainan coal mine, China," Journal of the Southern African Institute of Mining and Metallurgy, vol. 116, no. 5, pp. 431-440, 2016.

[17] H. Yan, J. Zhang, N. Zhou, S. Zhang, and X. Dong, "Shaft failure characteristics and the control effects of backfill body compression ratio at ultra-contiguous coal seams mining," Environmental Earth Sciences, vol. 77, no. 12, 2018.

[18] H. Yan, J. Zhang, S. Zhang, and N. Zhou, "Physical modeling of the controlled shaft deformation law during the solid back- fill mining of ultra-close coal seams," Bulletin Of Engineering Geology And The Environment, vol. 78, no. 5, pp. 3741-3754, 2019.

[19] H. Y. Liu, S. J. Wang, Q. B. Zeng, and B. Hu, "An artificial neural network forecast model for shaft lining non-mining fracture," Hydrogeology \& Engineering Geology, vol. 32, no. 2, pp. 65-67, 2005.

[20] L. Kong, Dynamic Analysis on the Stability of the Freeze Shaft Lining in Thick Top Soil, Shandong University of Science and Technology, Qingdao, China, 2004.

[21] X. G. Huang and J. Q. Guo, "Monitoring and measurement of shaft stability of west ventilation shaft in Gaokeng Mine," Coal Science and Technology, no. 12, pp. 14-16, 2001.

[22] C. L. Liu, Y. Li, and Y. C. Xu, "Stability appraisal and fracture forecast of coal mine shaft," Coal and Chemical Industry, vol. 36, no. 11, pp. 12-14+17, 2013.

[23] Y. C. Xu, Y. B. Gao, J. H. Li, and W. Z. Gu, "Improvement and application of mine shaft safety evaluation system," Coal Science and Technology, vol. 44, no. 10, pp. 95-101, 2016.

[24] X. Lyu and W. Wang, "Deformation Monitoring and Stability Analysis of Shaft Lining in Weakly Cemented Stratum," Advances in Civil Engineering, vol. 2018, Article ID 8462746, 12 pages, 2018.

[25] X. Wang, G. Wang, Y. Wu, Y. Xu, and H. Gao, "Comprehensive assessment of regional water usage efficiency control based on game theory weight and a matter-element model," Water, vol. 9, no. 2, p. 113, 2017.

[26] J. Zhao, J. Jin, J. Zhu et al., "Water resources risk assessment model based on the subjective and objective combination weighting methods," Water Resources Management, vol. 30, no. 9, pp. 3027-3042, 2016.

[27] C. Lai, X. Chen, X. Chen, Z. Wang, X. Wu, and S. Zhao, "A fuzzy comprehensive evaluation model for flood risk based on the combination weight of game theory," Natural Hazards, vol. 77, no. 2, pp. 1243-1259, 2015.

[28] X. Liang, W. Liang, L. Zhang, and X. Guo, "Risk assessment for long-distance gas pipelines in coal mine gobs based on structure entropy weight method and multi-step backward cloud transformation algorithm based on sampling with replacement," Journal of Cleaner Production, vol. 227, pp. 218-228, 2019.

[29] M. M. Sahoo, K. C. Patra, J. B. Swain, and K. K. Khatua, "Evaluation of water quality with application of Bayes' rule and entropy weight method," European Journal of Environmental and Civil Engineering, vol. 21, no. 6, pp. 730-752, 2017.

[30] X. Wang, W. Zhao, X. Liu et al., "Identification of water inrush source from coalfield based on entropy weight-fuzzy variable set theory," Journal of China Coal Society, vol. 40, no. 9, pp. 2433-2439, 2017.

[31] Z. Q. Chen, Y. M. Wang, S. M. Chen, and P. Niu, "Stability analysis of goaf based on entropy weight method and fuzzy theory," Mining Research and Development, vol. 39, no. 5, pp. 39-43, 2019.

[32] Q. Wu, Y. Liu, D. Liu, and W. Zhou, "Prediction of floor water inrush: the application of GIS-based AHP vulnerable index method to Donghuantuo coal mine, China," Rock Mechanics and Rock Engineering, vol. 44, no. 5, pp. 591-600, 2011.

[33] L. Chen, X. Feng, D. Xu, W. Zeng, and Z. Zheng, "Prediction of water inrush areas under an unconsolidated, confined aquifer: the application of multi-information superposition based on GIS and AHP in the Qidong coal mine, China," Mine Water and the Environment, vol. 37, no. 4, pp. 786-795, 2018. 
[34] J. Xu, P. Feng, and P. Yang, "Research of development strategy on China's rural drinking water supply based on SWOT-TOPSIS method combined with AHP-Entropy: a case in Hebei Province," Environmental Earth Sciences, vol. 75, no. 1, p. 58, 2016.

[35] W. Zhang, B. Li, and H. Yu, "The correlation analysis of mine roof water inrush grade and influence factors based on fuzzy matter-element," Journal of Intelligent \& Fuzzy Systems, vol. 31, no. 6, pp. 3163-3170, 2016.

[36] X. Wang, H. Yu, P. Lv, C. Wang, J. Zhang, and J. Yu, “Seepage Safety assessment of concrete gravity Dam based on matterelement extension model and FDA," Energies, vol. 12, no. 3, p. 502, 2019.

[37] P. Li, S. He, X. He, and R. Tian, "Seasonal hydrochemical characterization and groundwater quality delineation based on matter element extension analysis in a paper wastewater irrigation area, Northwest China," Exposure and Health, vol. 10, no. 4, pp. 241-258, 2018.

[38] C. Wang, A. Wu, H. Lu, T. Bao, and X. Liu, "Predicting rockburst tendency based on fuzzy matter-element model," International Journal of Rock Mechanics and Mining Sciences, vol. 75, pp. 224-232, 2015.

[39] B. Li, G. Yang, R. Wan, and G. Hörmann, "Dynamic water quality evaluation based on fuzzy matter-element model and functional data analysis, a case study in Poyang Lake," Environmental Science and Pollution Research, vol. 24, no. 23, pp. 19138-19148, 2017.

[40] S. Dai and D. Niu, "Comprehensive evaluation of the sustainable development of power grid enterprises based on the model of fuzzy group ideal point method and combination weighting method with improved group order relation method and entropy weight method," Sustainability, vol. 9, no. 10, article 1900, 2017.

[41] H. J. Xu, B. F. Zhao, Y. Zhou, and S. Y. Liu, "Evaluation on water disaster from roof strata based on the entropy-weight and matter-element extension model," Journal of Mining \& Safety Engineering, vol. 35, no. 1, pp. 112-117, 2018.

[42] W. B. Guo, C. Li, S. C. Zhang, and D. C. Liu, "Hand in scene of water and sands bursting of ultra-thick alluvium and study on the surface subsidence monitoring," Journal of Henan Polytechnic University (Natural Science), vol. 36, no. 3, pp. 9-14, 2017.

[43] T. T. Zhang, B. K. Sun, B. D. Wang, and P. Fang, "Cause analysis of synchronous subsidence of deep unconsolidated layer shaft and surface," Safety in Coal Mines, vol. 48, no. 3, pp. 175-177+181, 2017.

[44] B. Bai and W. Q. Zhang, "Study on time series model of loose layer settlement in thick loose layer mining," Coal Technology, vol. 37, no. 9, pp. 176-177, 2018.

[45] J. H. Lin, Research on the Stress Status of Vertical Shaft-Lining under the Fast-Time Hydrophobic Drainage Process in Deep Alluvium, China University of Mining and Technology, China, 2016.

[46] Y. Wang, L. Yu, T. Yin, L. Yu, and Z. Huo, "Stability Analysis of Partially Submerged Landslide with the Consideration of the Relationship between Porewater Pressure and Seepage Force," Geofluids, vol. 2018, Article ID 9145830, 9 pages, 2018.

[47] G. Walton, E. Kim, S. Sinha, G. Sturgis, and D. Berberick, "Investigation of shaft stability and anisotropic deformation in a deep shaft in Idaho, United States," International Journal of Rock Mechanics and Mining Sciences, vol. 105, pp. 160-171, 2018. 

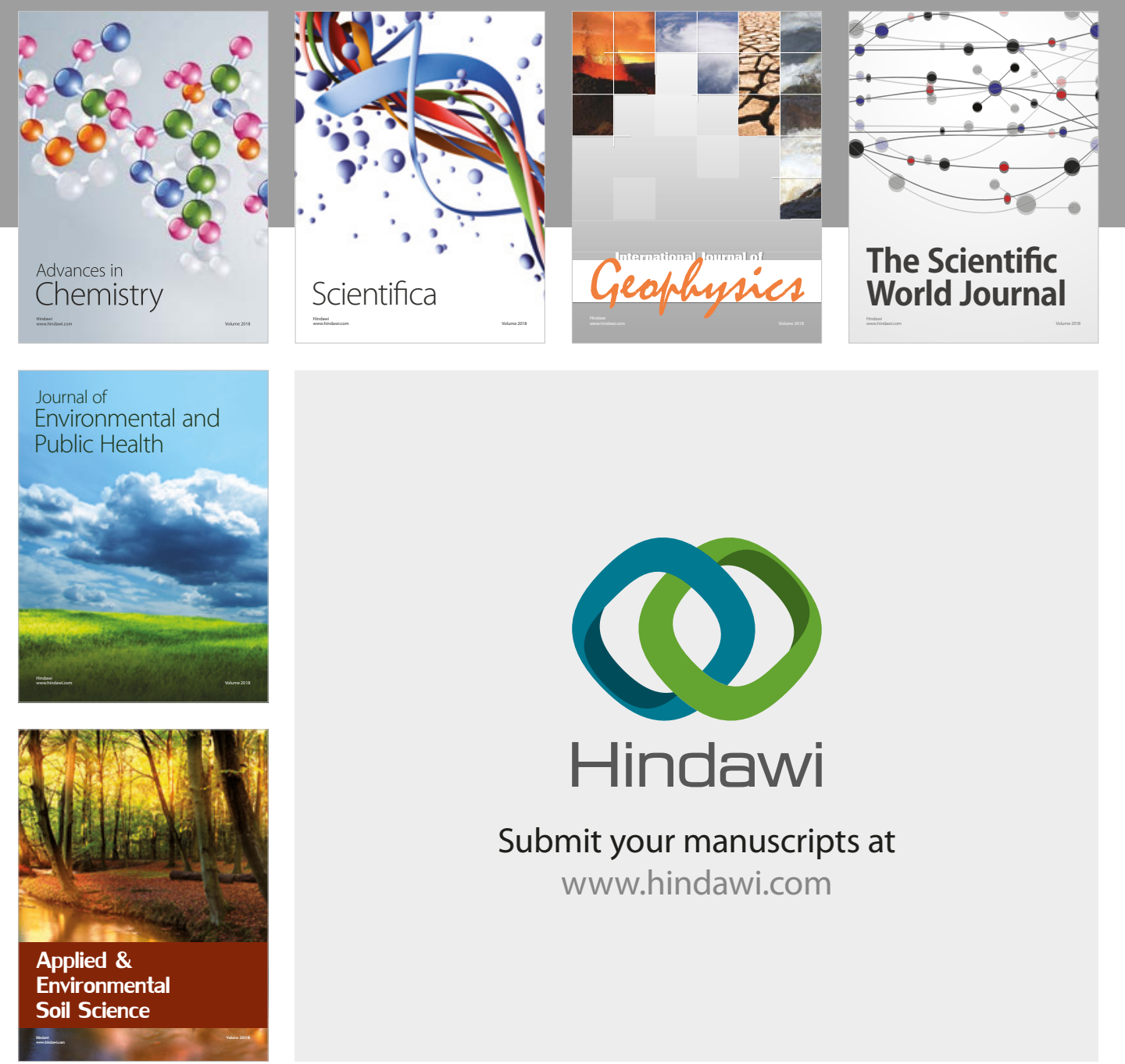

The Scientific

\section{World Journal}
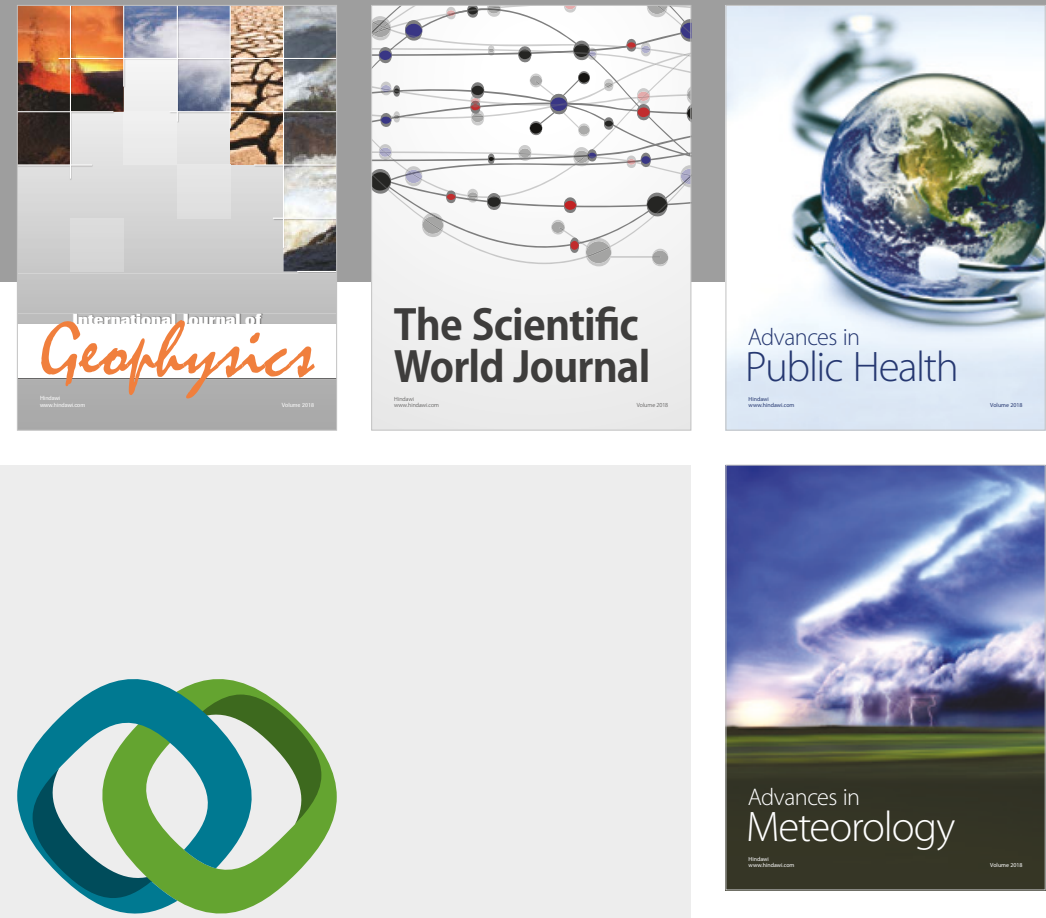

Advan

Public Health

\section{Hindawi}

Submit your manuscripts at

www.hindawi.com
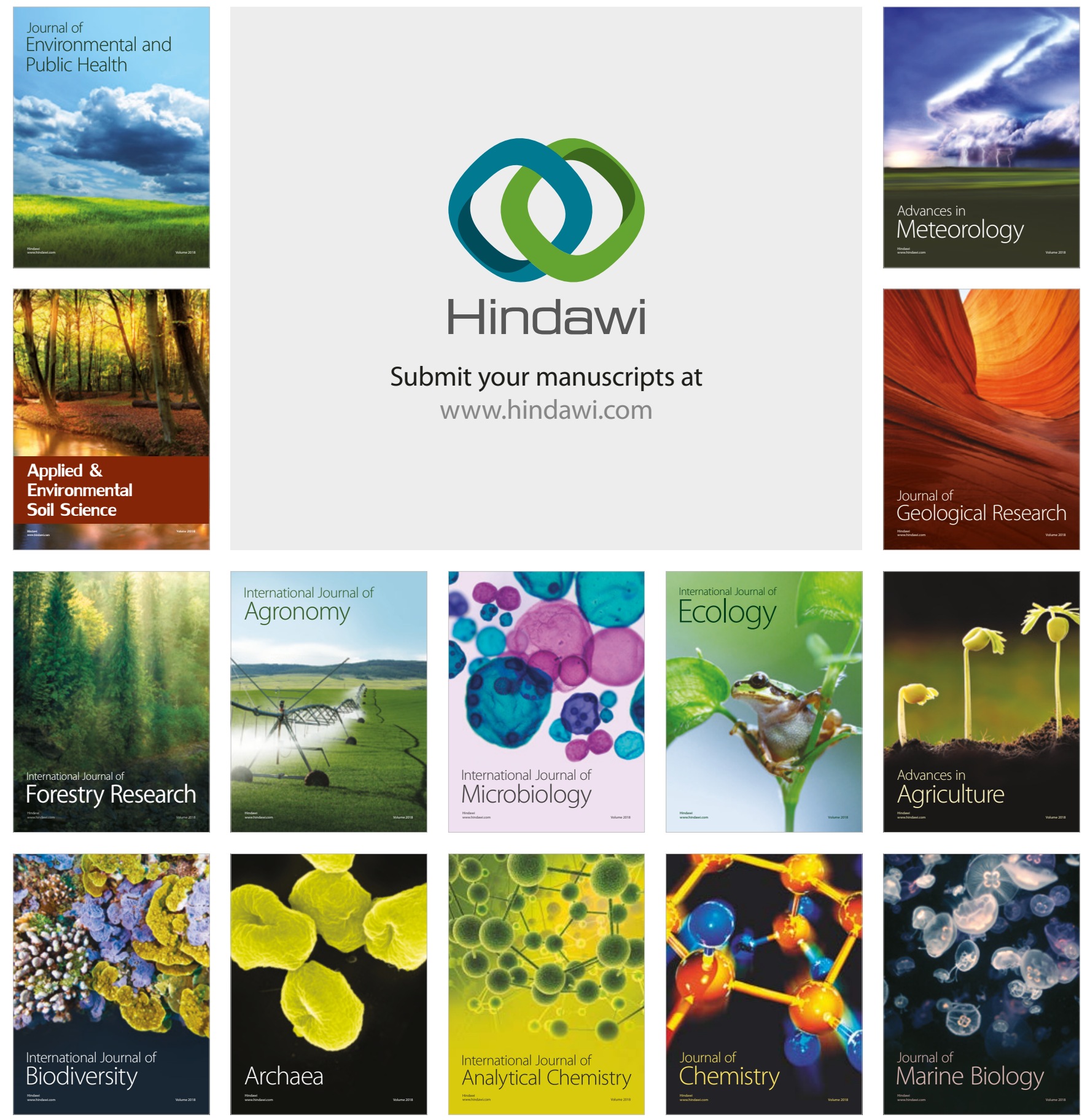